\title{
Wave Loads Computation for Offshore Floating Hose Based on Partially Immersed Cylinder Model of Improved Morison Formula
}

\author{
Shi-fu Zhang ${ }^{1, *}$, Chang Chen ${ }^{2}$, Qi-xin Zhang ${ }^{2}$, Dong-mei Zhang ${ }^{1}$ and Fan Zhang ${ }^{3}$ \\ ${ }^{I}$ National Engineering Research Center for Disaster \& Emergency Relief Equipment, Logistic Engineering University, \\ ChongQing, 401311, China; ${ }^{2}$ Deptartment of Petroleum Supply Engineering, Logistic Engineering University, \\ ChongQing, 401311, China; ${ }^{3}$ Deptartment of Mechanic and Electric Engineering, Logistic Engineering University, \\ ChongQing, 401311, China
}

\begin{abstract}
Aimed at wave load computation of floating hose, the paper analyzes the morphologic and mechanical characteristics of offshore hose by establishing the partially immersed cylender model, and points out that the results of existing Morison equation to calculate the wave loads of floating hose is not precise enough. Consequently, the improved Morison equation has been put forward based on its principle. Classical series offshore pipeline has been taken as example which applied in the water area of different depth. The wave loads of pipeline by using the improved Morison equation and compared the calculation results with the existing Morison equation. Calculations for wave loads on pipelines in different depth were accomplished and compared by the improved Morison equation and the existing Morison equation. Results show that the improved Morison equation optimizes the accuracy of the computation of wave load on floating hose. Thus it is more suitable for analyzing the effects of wave loads on floating hose and useful for mechanic analysis of offshore pipeline.
\end{abstract}

Keywords: Method improvement, morison equation, offshore floating hose, wave load.

\section{INTRODUCTION}

The offshore floating hose is widely used in port and ocean engineering due to its light weight, high tensile strength and ability to achieve rapid deployment and withdrawal. As an important part of FPSO system, floating hose are used to deliver the crude oil which extracted from offshore field to shuttle tankers. Moreover, it has played an important role in the implementation of water-oil replenishment at sea for The Navy warships. Whether in the state of transporting oil or not, the hose are always floating on the sea under buoyancy for its light weight. Therefore, the floating hose are vulnerable to ocean current and waves.

Morison's equation (Morison et al. 1950) is used for estimating the hydrodynamic forces on the relatively slender members of offshore structures and is perhaps the most widely quoted and used equation in offshore engineering. Julian Wolfram [1] has proposed an alternative approach to linearization which yields corresponding linear forms that produce unbiased estimates for the outputs from nonlinear equations. The linearization factors for Morison's equation have been found for the cases of expected fatigue damage and expected extreme environmental load. The Morison equation inertia and drag coefficients were estimated by Julca Avila [2] with two parameter identification methods that are the weighted and the ordinary least-squares procedures. Error analysis showed that the ordinary least-squares provided better accuracy and, therefore, was used to evaluate the ratio between inertia and drag forces for a range of Keulegan-Carpenter and Reynolds numbers. Two smallscale field experiments on the effectiveness of Morison's equation have been carried out by Paolo Boccotti [3]. The agreement between Morison's equation and the observation data is valuable which proved the method presented in an earlier paper [4] to be suitable for field experiments and is recommended for future work. Yang, Wanli [5] presented the expanded Morison equation, which can afford hydrodynamic pressure caused by inner water and outer water simultaneously. The practical application of the expanded Morison equation has been explored through analyzing a continuous rigid-framed deep water bridge. The results demonstrate that it is an approximate, convenient and efficient way to estimate the hydrodynamic pressure caused by both inner and outer water under earthquakes.

Many researches have been conducted the wave loads acting on offshore structures and the offshore structures are classified as large or small scale one according to the influence of wave movement on them. At present, offshore isolated pile [6-8] and submarine oil pipeline [9-11] are main subjects of wave forces effects on small-size offshore structures. Researches aimed at the calculation of wave load of floating hose are relatively rare and Morison formula [12-14] which includes the inertia term (depending on wave acceleration) and the drag term (depending on square velocity) 
directly brings about inaccuracy. Thus, it is necessary to improve the Morison equation under the condition of the shape and loading features of hose floating on the sea. Improving the accuracy of calculation of wave loads on hose is of vital importance for better analysis of the effects of marine hose on wave loads and safe use of floating hose.

\section{MORISON EQUATION}

Morison equation, a semiempirical formula based on flow theory, has been widely used in the calculation of wave loads of small-scale marine structure whose ratio of radius and length is less than 0.2. The theory assumes that the small-scale marine structure has no significant effect on the wave motion, and that the effects of waves on the structure is mainly composed of viscous effect and the added mass effect.

In case of a cylinder upright on the sea suffering the waves from the positive direction of axis $\mathrm{x}$ in which the intersection of seafloor and axis of cylinder is taken as the origin of XOZ coordinate system. Morison holds that the waveinduced force which offshore structures are subjected to the inertia term (depending on wave acceleration) and the drag term (depending on square velocity). The derivation of the formula on the calculation of wave loads is presented as follow just taking one supposition as the premise that the drag force caused by wave movement and the one due to the unidirectional steady flow has the same mechanism.

$$
\begin{aligned}
f_{H} & =f_{D}+f_{I} \\
& =\frac{1}{2} C_{D} \rho A u_{x}\left|u_{x}\right|+\left(1+C_{m}\right) \rho \vec{V}_{0} \frac{\partial u_{x}}{\partial t} \\
& =\frac{1}{2} C_{D} \rho D u_{x}\left|u_{x}\right|+C_{M} \rho \frac{\pi D^{2}}{4} \frac{\partial u_{x}}{\partial t}
\end{aligned}
$$

Where $f_{H}$ is the horizontal wave forces acting on certain height of cylinder, $f_{D}$ is the horizontal drag force, $f_{I}$ is the horizontal inertial force, $C_{D}$ is the drag coefficient, $V_{0}$ is the volume of displacement of unit height, $A$ is projection area of unit height vertical to the wave motion direction, $u_{x}$ is the velocity in horizontal direction of wave particle, $C_{m}$ is the added mass coefficient, $C_{M}$ is the mass coefficient, and $D$ is the diameter of the cylinder.

\section{THE IMPROVED MORISON EQUATION}

Slender cylinder is often used as basic structure of ocean engineering and the deducing of its Morison equation are also based on the cylinder model. The diameter of floating hose is much smaller than the wavelength of the incident wave. Thus, it is assumed that the floating hose has no significant influence on wave movement and the effect of waves on the structure is mainly composed of viscous effect and the added mass effect. Offshore floating hose is flat with nothing in it but turn into cylindrical shape in oil-transferring state and always floating in the sea due to its light material and low density conveyance medium, as shown in Fig. (1). The formation and change of the drag force is closely related with the boundary layer formed on the surface of the column body. In other words, it is closely related with the projected area of the column per unit length in the vertical direction.
Shown as Fig. (2), only part of the hose is immersed in sea and the height below the sea level is less than the diameter of the pipe. The relations are as follows.

$\left\{\begin{array}{l}A_{1}=1 \times h \\ A_{2}=1 \times D \\ A_{1}<A_{2}\end{array}\right.$

Where $A_{1}$ represents the projected area of floating pipe per unit length in the vertical direction of the flow, $A_{2}$ represents the projected area of vertical cylinders per unit length in the vertical direction of the flow.

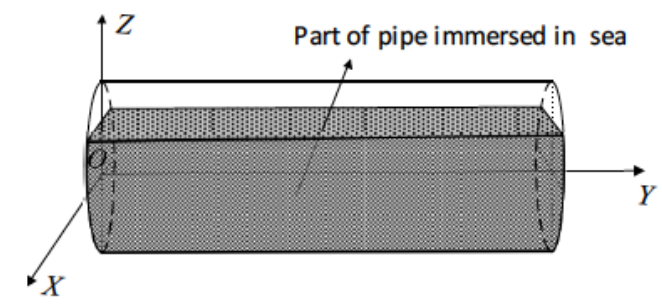

Fig. (1). The schematic diagram of offshore floating pipelines.

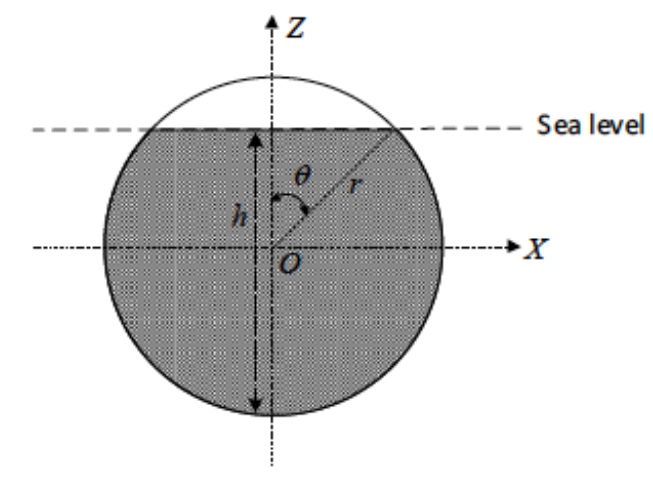

Fig. (2). The sectional view of offshore floating pipelines.

Flow inertia force is caused by the disturbance of fluid pressure distribution due to the existence of structure. The volume of displaced fluid and pressure distribution without structure are key factors of flow inertia force. As is shown in diagram 1, the volume of displaced fluid of offshore floating pipe is less than that of vertical cylinders per unit length, and relationship can be described as follows.

$\left\{\begin{array}{l}V_{1}=1 \times S_{1} \\ V_{0}=1 \times \frac{\pi D^{2}}{4} \\ V_{1}<V_{0}\end{array}\right.$

Where $V_{1}$ represents the volume of displaced fluid of offshore floating pipe per unit length, $S$ represents the projected area of per unit floating pipe in the vertical direction of center axis of pipe, $V_{0}$ represents the volume of displacement of per unit vertical cylinders. According to the analysis of key factors closely related to wave loads, a conclusion can be drawn that using the existing Morison formula to calculate the wave load of floating hose is inaccurate. Thus, it is necessary to improve the Morison equation aiming at the calculation of wave load of floating hose. 
Where $h$ represents the height of immersed pipe below the sea level, $\theta$ represents half of the corresponding central angle of the bow-shaped above sea level.

Centre of mass is taken as the origin of $\mathrm{XOZ}$ coordinate system and the wave, ocean current, wind, gravity and buoyancy loads are applied to the partially submerged pipe. Stress analysis of floating pipe has been represented in the Fig. (3).

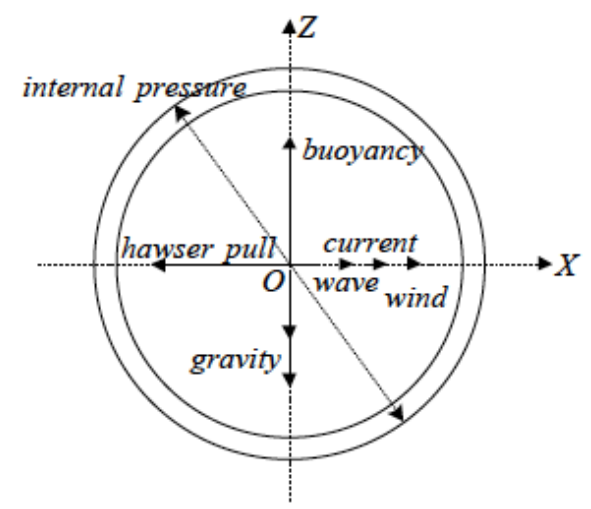

Fig. (3). The stress analysis of offshore floating pipelines.

This is an extreme case where the loads of current, wave and wind has the same direction, resulting in the maximum horizontal load on the pipe. According to the force balance principle, the following formula could be formed.

$$
\left\{\begin{array}{l}
F_{B}=G_{1}+G_{2} \\
F_{P}=F_{\text {wind }}+F_{\text {wave }}+F_{\text {current }}
\end{array}\right.
$$

Where $F_{B}$ represents the buoyancy loads of pipe, $F_{P}$ represents the anchor force in the horizontal direction, $G_{1}$ represents the weight of floating hose, $G_{2}$ represents the weight of oil transporting in the hose. The specific forms of each load are shown in formula (5).

$$
\left\{\begin{array}{l}
F_{B}=S_{1} \times L_{1} \times \rho_{1} \\
G_{1}=\pi\left[\left(\frac{D}{2}\right)^{2}-\left(\frac{D}{2}-d_{1}\right)^{2}\right] \times L_{1} \times \rho_{2} \\
G_{2}=\pi\left(\frac{D}{2}-d_{1}\right)^{2} \times L_{1} \times \rho_{3}
\end{array}\right.
$$

Where $S_{1}$ represents the projected area of per unit floating pipe in the vertical direction of center axis of pipe, $L_{1}$ represents the unit length, $\rho_{1}$ represents the density of seawater, $\rho_{2}$ represents the density of floating hose, $\rho_{3}$ represents the density of oil transporting in the hose, $D$ represents the outer diameter of floating hose, $d_{1}$ represents the thickness of floating hose.

$$
S_{1}=\frac{\pi\left(\frac{D}{2}-d_{1}\right)^{2} \times L_{1} \times \rho_{3}+\pi\left[\left(\frac{D}{2}\right)^{2}-\left(\frac{D}{2}-d_{1}\right)^{2}\right] \times L_{1} \times \rho_{2}}{L_{1} \times \rho_{1}}
$$

Thus, the flow inertia force acting on the floating hose could be described as follows.

$$
\begin{aligned}
f_{I}^{\prime} & =C_{M} \rho_{1} V_{1} \frac{\partial u_{x}}{\partial t} \\
& =C_{M} \rho_{1} S_{1} \frac{\partial u_{x}}{\partial t}
\end{aligned}
$$

The shaded part area in Fig. (2) can be described in the other way as follows.

$$
\left\{\begin{array}{l}
S_{1}=S_{\text {sector }}+S_{\text {triangle }} \\
S_{\text {sec } t o r}=\frac{2 \pi-2 \theta}{2 \pi} \times \pi r^{2}=\left(\pi-a \cos \frac{h-r}{r}\right) r^{2} \\
S_{\text {triangle }}=(h-r) \times \sqrt{r^{2}-(h-r)^{2}} \\
r=\frac{D}{2}
\end{array}\right.
$$

The height of immersed pipe below the sea level can be calculated by combining two equations and the flow drag force applying on the floating hose could be described as follows.

$$
\begin{aligned}
f_{D}^{\prime} & =\frac{1}{2} C_{D} \rho_{1} A_{1} u_{x}\left|u_{x}\right| \\
& =\frac{1}{2} C_{D} \rho_{1} h u_{x}\left|u_{x}\right|
\end{aligned}
$$

To sum up, the improved Morison equation which adapted for the analysis for offshore floating hose can be described as follows.

$$
\begin{aligned}
f_{H}^{\prime} & =f_{D}^{\prime}+f_{I}^{\prime} \\
& =\frac{1}{2} C_{D} \rho_{1} A_{1} u_{x}\left|u_{x}\right|+C_{M} \rho_{1} V_{1} \frac{\partial u_{x}}{\partial t} \\
& =\frac{1}{2} C_{D} \rho_{1} h u_{x}\left|u_{x}\right|+C_{M} \rho_{1} S_{1} \frac{\partial u_{x}}{\partial t}
\end{aligned}
$$

Where $u_{x}$ represents the horizontal velocity of wave particle at the center of the hose, $\frac{\partial u_{x}}{\partial t}$ represents the horizontal acceleration of wave particle at the center of the hose.

\section{WAVE THEORY}

Airy wave theory, Stokes wave theory, solitary wave theory and conical wave theory are used to calculate the wave forces acting on a offshore structure based on different situations frequently. Zhu Yan-rong [15] presented the application conditions of different wave theory as follow.

Choosing the suitable drag and mass coefficient is crucial to calculate wave load of offshore structure by using the Morison equation. Many domestic experts and scholars have conducted a lot of works on optimization of those parameters and some recommended values are listed in Table 2. Usually, it is essential to carry on the hydrodynamic experiment in water so as to determine the value of specific coefficient [16].

\section{EXAMPLES}

Floating hose is widely used in exploitation and transportation of offshore oil field. The article calculated the wave 
loads of widely used offshore pipe in the fourth sea level by using Morison equation and improved Morison equation respectively. The parameters of pipeline and level 4 waves are listed in Tables 3 and $\mathbf{4}$.

The height $h$ and the projected area $S_{1}$ can be obtained by taking above parameters into the formula (6) and (8). The result is listed in formula (11).

$$
\left\{\begin{array}{l}
h=95.1 \mathrm{~mm} \\
\frac{h}{D}=0.834 \\
S_{1}=0.0091 \mathrm{~m}^{2}
\end{array}\right.
$$

Hence, $83.4 \%$ of floating pipeline is immersed in the sea. According to the applicable conditions of wave theory presented in Table 1, the Airy theory should be chosen when the water is more than 4 meters deep and the Stokes theory will be more suitable when it is between 2 and 4 meters deep. Code of Hydrology for Sea Harbour pressed in 1998[17] has settled the value of $C_{D}$ and $C_{M}$ in China sea area.

Table 1. The applicable conditions of wave theory.

\begin{tabular}{|c|c|}
\hline Condition & Wave Theory \\
\hline \hline$d / L \geq 0.2, H / L \leq 0.2$ & Airy wave theory \\
\hline $0.1<d / L<0.2, H / L \geq 0.2$ & Stokes wave theory \\
\hline $0.04 \sim 0.05<d / L<0.1$ & $\begin{array}{l}\text { Conical wave theory } \\
\text { Solitary wave theory }\end{array}$ \\
\hline
\end{tabular}

$\left\{\begin{array}{l}C_{D}=1.2 \\ C_{M}=2\end{array}\right.$

\subsection{Airy Wave Theory}

Taking depth equal 6 as an example, the Airy theory is more suitable for wave loads calculation of offshore hose than others. The velocity and acceleration of wave partials in the horizontal direction should satisfy the condition of formula (13).

$$
\left\{\begin{array}{l}
u_{x}=\frac{\partial \varphi}{\partial x}=\frac{H g k}{2 \omega} \frac{\cosh (k(z+d))}{\cosh (k d)} \cos (k x-\omega t) \\
a_{x}=\frac{\partial u_{x}}{\partial t}=\frac{2 \pi^{2} H}{T^{2}} \frac{\cosh (k(z+d))}{\sinh (k d)} \sin (k x-\omega t)
\end{array}\right.
$$

Where $u_{x}$ represents the horizontal velocity of wave partial, $a_{x}$ represents the horizontal acceleration of wave partial, $\varphi$ represents the velocity potential of wave partial, $k$ represents wave number which presented in formula (14).

$k=\frac{2 \pi}{T}$

The velocity and acceleration of wave partials in the vertical direction should meet the condition of formula (15).

$$
\left\{\begin{array}{l}
u_{z}=\frac{\partial \varphi}{\partial z}=\frac{H g k}{2 \omega} \frac{\sinh (k(z+d))}{\cosh (k d)} \sin (k x-\omega t) \\
a_{z}=\frac{\partial u_{z}}{\partial t}=-\frac{2 \pi^{2} H}{T^{2}} \frac{\sinh (k(z+d))}{\sinh (k d)} \cos (k x-\omega t)
\end{array}\right.
$$

\begin{tabular}{|c|c|c|c|c|}
\hline Wave Theory & $\mathbf{C}_{D}$ & $\mathbf{C}_{M}$ & Comments & References \\
\hline \multirow{2}{*}{ Linear theory } & 1.0 & 0.95 & Mean values for ocean wave data on $13-24$ in cylinders. & Wiegel et al. (1957) \\
\hline & $1.0-1.4$ & 2.0 & $\begin{array}{l}\text { Recommended design values based on statistical analysis } \\
\text { of published data. }\end{array}$ & $\begin{array}{l}\text { Agerschou and Edens } \\
\text { (1965) }\end{array}$ \\
\hline Stokes $3^{\text {rd }}$ order & 1.34 & 1.6 & Mean values for oscillatory flow for $2-3$ in cylinders. & $\begin{array}{l}\text { Keulegan and carpenter } \\
\text { (1958) }\end{array}$ \\
\hline Stokes $5^{\text {th }}$ order & $0.8-1.0$ & 2.0 & $\begin{array}{c}\text { Recommended values based on statistical analysis of } \\
\text { published data. }\end{array}$ & $\begin{array}{l}\text { Agerschou and Edens } \\
\text { (1965) }\end{array}$ \\
\hline
\end{tabular}

Table 2. The recommended values of $C_{D}$ and $C_{M}$.

Table 3. Parameters of floating pipeline.

\begin{tabular}{|c|c|c|c|c|}
\hline $\boldsymbol{D}(\mathrm{mm})$ & $\boldsymbol{d}(\mathbf{m m})$ & $\rho_{1}\left(\mathrm{~g} / \mathrm{cm}^{3}\right)$ & $\rho_{2}\left(\mathrm{~g} / \mathrm{cm}^{3}\right)$ & $\rho_{3}\left(\mathrm{~g} / \mathrm{cm}^{3}\right)$ \\
\hline \hline 114 & 6 & 1.025 & 1.25 & 0.83 \\
\hline
\end{tabular}

Table 4. Parameters of level 4 waves.

\begin{tabular}{|c|c|c|c|c|}
\hline $\boldsymbol{L}(\boldsymbol{m})$ & $\boldsymbol{T}(\boldsymbol{s})$ & $\omega\left(\boldsymbol{s}^{-1}\right)$ & $\boldsymbol{c}(\boldsymbol{m} / \boldsymbol{s})$ & $\boldsymbol{H}(\boldsymbol{m})$ \\
\hline \hline 20 & 3.57 & 1.93 & 5.6 & 1.25 \\
\hline
\end{tabular}


For the calculation of wave load by Morison equation, parameters of level 4 waves in Table 4 are used to calculate the velocity and acceleration of wave partials in formula (13) and formula (15) at the beginning. After that, the wave load could be worked out by submitting the above result along with the external diameter and cross section area of the pipe to formula (1). For the calculation of wave load with Improved Morison equation, the velocity and acceleration of wave partials still need to be figured out. Afterwards, the wave load could be calculated by submitting those results along with the height $h$ and the projected area $S_{1}$ to formula (10) by using the Matlab program. Extreme value of wave loads by using the Morison theory and Improved Morison theory are listed in Table 5.

Wave load variations are shown in Fig. (4) and Fig. (5) by using the Matlab program.

\subsection{Stokes Two Order Wave Theory}

Taking depth equal 3 as an example, the Stokes theory should be chosen for wave loads calculation of offshore hose in this situation. The velocity and acceleration of wave partials in the horizontal direction should satisfy the condition of formula (16).

$$
\left\{\begin{aligned}
u_{x}= & \frac{\partial \varphi}{\partial x}=\frac{H \pi}{T} \frac{\cosh (k(z+d))}{\sinh (k d)} \cos (k x-\omega t) \\
& +\frac{3}{4}\left(\frac{H \pi}{T}\right)\left(\frac{H \pi}{L}\right) \frac{\cosh (2 k(z+d))}{\sinh ^{4}(k d)} \cos 2(k x-\omega t) \\
a_{x}= & \frac{\partial u_{x}}{\partial t}=2\left(\frac{H \pi^{2}}{T^{2}}\right) \frac{\cosh (k(z+d))}{\sinh (k d)} \sin (k x-\omega t) \\
& +3\left(\frac{H \pi^{2}}{T^{2}}\right)\left(\frac{H \pi}{L}\right) \frac{\cosh (2 k(z+d))}{\sinh ^{4}(k d)} \sin 2(k x-\omega t)
\end{aligned}\right.
$$

The velocity and acceleration of wave partials in the vertical direction should satisfy the relationship as formula (17).

$$
\left\{\begin{aligned}
u_{z}= & \frac{\partial \varphi}{\partial z}=\frac{H \pi}{T} \frac{\sinh (k(z+d))}{\sinh (k d)} \sin (k x-\omega t) \\
& +\frac{3}{4}\left(\frac{H \pi}{T}\right)\left(\frac{H \pi}{L}\right) \frac{\sinh (2 k(z+d))}{\sinh ^{4}(k d)} \sin 2(k x-\omega t) \\
a_{z}= & \frac{\partial u_{z}}{\partial t}=-2\left(\frac{H \pi^{2}}{T^{2}}\right) \frac{\sinh (k(z+d))}{\sinh (k d)} \cos (k x-\omega t) \\
& -3\left(\frac{H \pi^{2}}{T^{2}}\right)\left(\frac{H \pi}{L}\right) \frac{\sinh (2 k(z+d))}{\sinh ^{4}(k d)} \cos 2(k x-\omega t)
\end{aligned}\right.
$$

Table 5. Extreme value of wave loads with the usage of Airy theory.

\begin{tabular}{|c|c|c|c|c|}
\hline \multirow{2}{*}{ Technique } & \multicolumn{2}{|c|}{ The Horizontal Wave Loads } & \multicolumn{2}{c|}{ The Vertical Wave Loads } \\
\cline { 2 - 5 } & Max Value & Mix Value & Max Value & Mix Value \\
\hline \hline Morison theory & 89.46 & -89.2 & 82.90 & -83.0 \\
\hline Improved Morison theory & 75.35 & -75.2 & 75.55 & -75.6 \\
\hline
\end{tabular}

The unit of values in above table is $\mathrm{N} / \mathrm{m}$. 


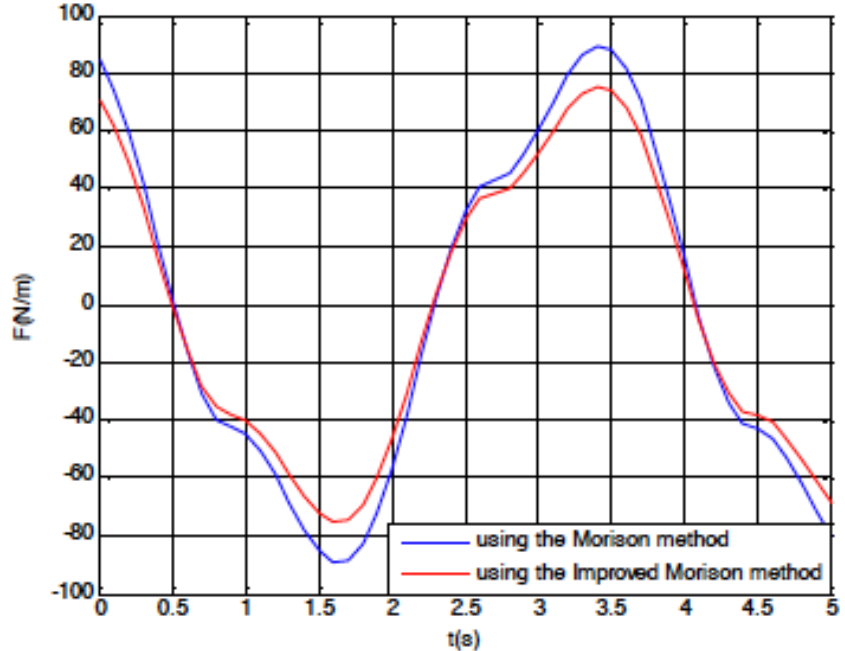

Fig. (4). The comparison of horizontal wave force between the use of the improved Morison equation and existing Morison equation in airy theory.

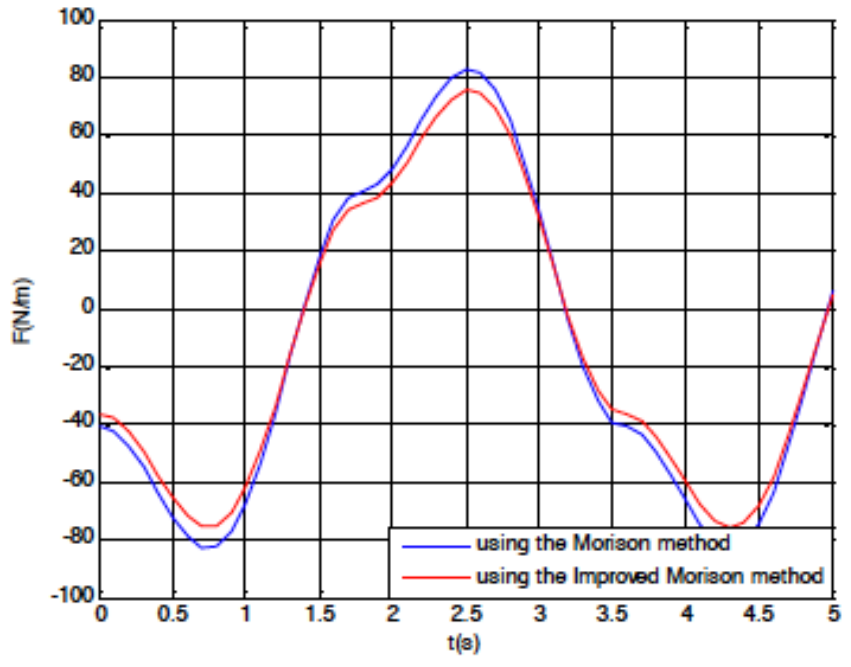

Fig. (5). The comparison of vertical wave force between the use of the improved Morison equation and existing Morison equation in airy theory.

Table 6. Extreme value of wave loads through the use of Stokes theory.

\begin{tabular}{|c|c|c|c|c|}
\hline \multirow{2}{*}{ Technique } & \multicolumn{2}{|c|}{ The Horizontal Wave Loads } & \multicolumn{2}{c|}{ The Vertical Wave Loads } \\
\cline { 2 - 5 } & Max Value & Mix Value & 123.01 & -124.42 \\
\hline \hline Morison theory & 257.48 & -88.95 & 103.39 & -104.94 \\
\hline Improved Morison theory & 215.59 & -74.76 & Max Value \\
\hline
\end{tabular}

The unit of values in above table is $\mathrm{N} / \mathrm{m}$.

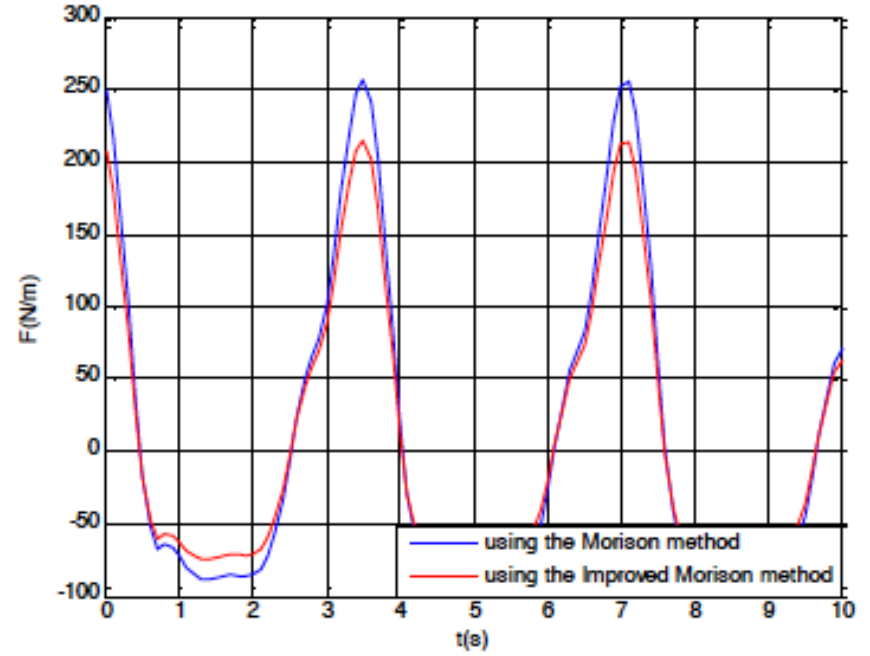

Fig. (6). The comparison of horizontal wave force between the use of the improved Morison equation and existing Morison equation in in Stokes theory.

The main reason for this phenomenon is that Morison equation is based on vertical cylinder model and supposes the infinitesimal section is completely immersed in water. Thus, the displacement volume is considered as cylinder volume and the projected area of per unit length in the vertical direction of the flow are considered as the external di-

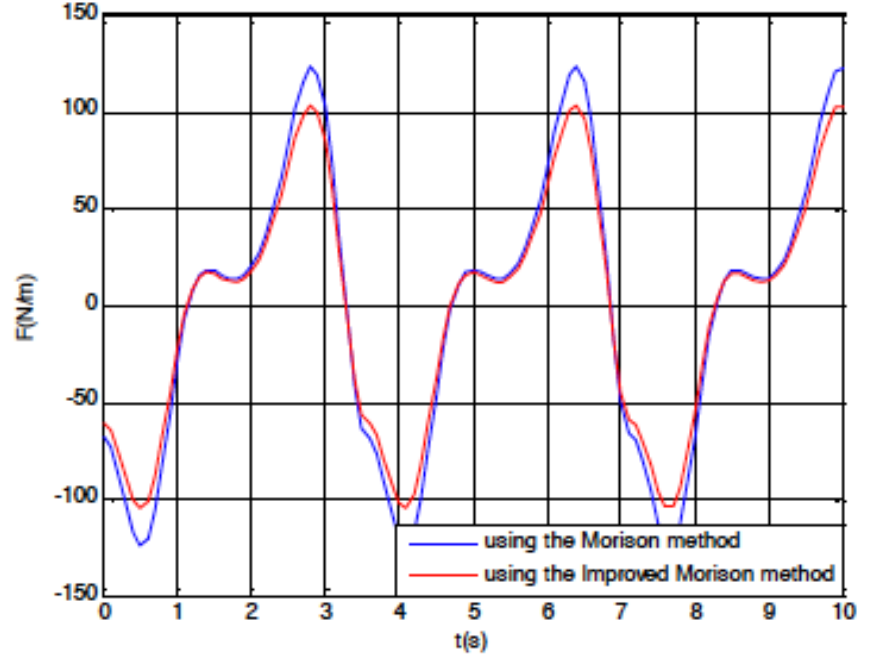

Fig. (7). The comparison of vertical wave force between the use of the improved Morison equation and existing Morison equation in Stokes theory.

ameter of the hose by default. However, the hoses are always floating on the sea under buoyancy whether they are in the state of transporting oil or not and only part of them are immersed in the sea. The displacement volume and the projected area of per unit length in the vertical direction of the flow is determined by the mechanical equilibrium in the 
Table 7. The wave load of floating hose in different depth.

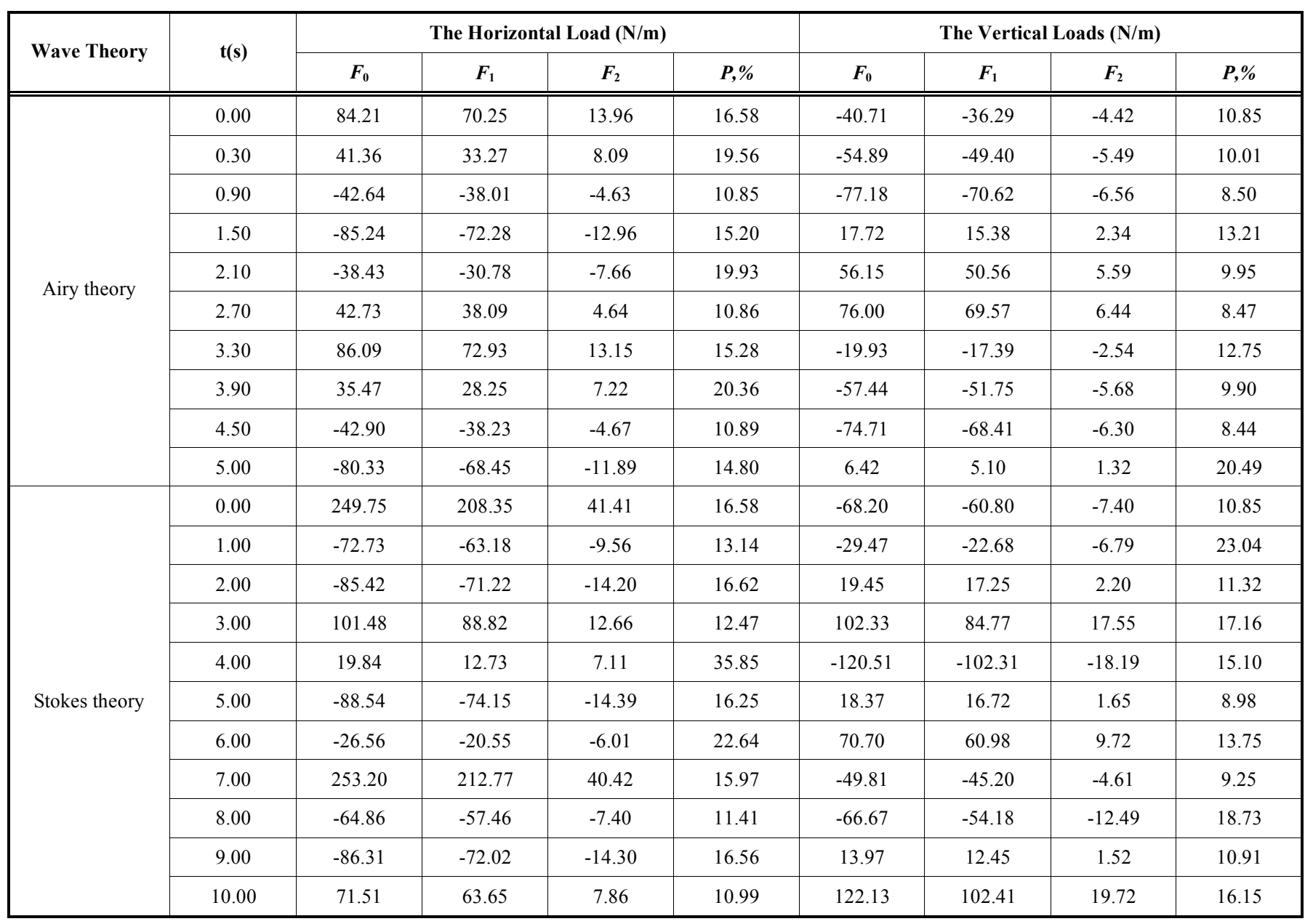

Table 8. Some characteristic value of the ratio $P$.

\begin{tabular}{|c|c|c|c|}
\hline Parameter & $\boldsymbol{P}_{\mathbf{1}}$ & $\boldsymbol{P}_{\mathbf{2}}$ & $\boldsymbol{P}_{\mathbf{4}}$ \\
\hline \hline Max value & 20.36 & 20.49 & 22.64 \\
\hline Average value & 15.43 & 11.26 & 15.26 \\
\hline
\end{tabular}

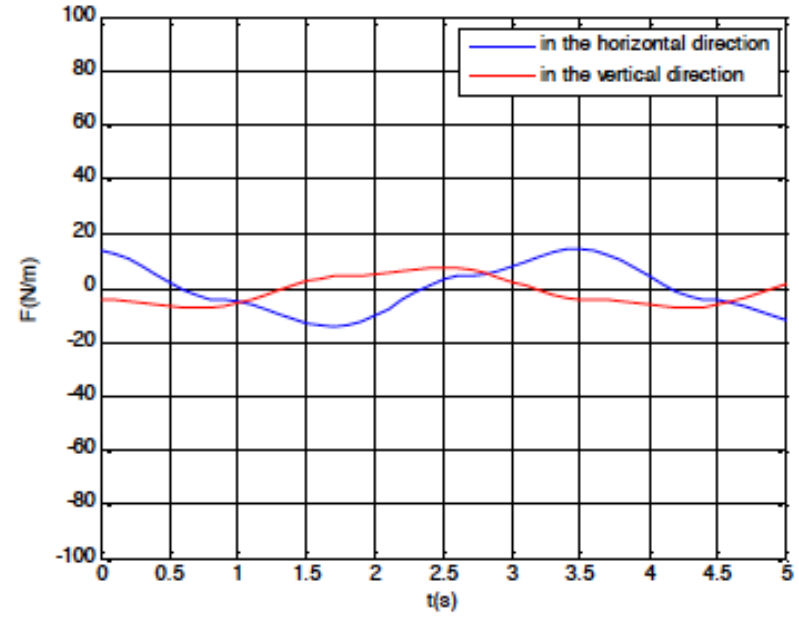

Fig. (8). The variation of wave load difference based on Airy theory.

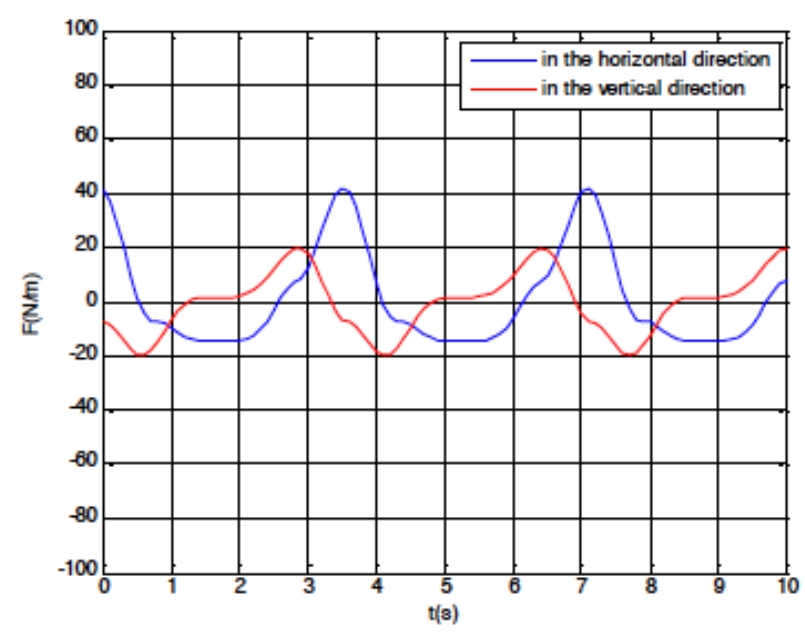

Fig. (9). The variation of wave load difference based on Stokes theory. 
vertical direction. Obviously, the displacement volume is smaller than cylinder volume per unit length and the projected area of per unit length is smaller than the default value. Hence, the wave load of floating hose in practical situation is smaller than the calculation based on Morison equation.

\section{CONCLUSION}

For the wave load of offshore floating hose, results based on the Morison equation are overrated. The Improved Morison equation is proposed by establishing the partially immersed cylinder model which contained morphologic and mechanical characteristics of floating hose. In case of the floating hose deployed in 6-meter deep and 3-meter deep water, the wave load based on improved Morison equation is more precisely than the previous one. The accuracy of wave loads can be improved about $15 \%$. Thus, the improved Morison equation is more precisely and meaningful for analysis of marine hose mechanics.

\section{CONFLICT OF INTEREST}

The authors confirm that this article content has no conflicts of interest.

\section{ACKNOWLEDGEMENTS}

This paper belongs to the project of the "Development and Industrialization for Emergency and Urban Drainage System of Mobile and Large Flow", No.2014BAK05B08; National Science and Technology Support Program.

\section{REFERENCES}

[1] J. Wolfram, "On alternative approaches to linearization and Morison's equation for wave forces", Proceedings of the Royal Society A: Mathematical, Physical and Engineering Sciences, vol. 455, pp. 2957-2974, 1999.

[2] J.P.J. Avila, and J.C. Adamowski, "Experimental evaluation of the hydrodynamic coefficients of a ROV through Morison's equation", Ocean Engineering, vol. 38, no. 17-18, pp. 2162-2170, 2011.
[3] P. Boccotti, F. Arena, V. Fiamma, and A. Romolo, "Two smallscale field experiments on the effectiveness of Morison's equation", Ocean Engineering, vol. 57, pp. 141-149, 2013.

[4] P. Boccotti, Field Experiment of Random-wave Forces on Vertical Cylinders. Computational Stochastic Mechanics Research Publishing, 2011, pp. 102-115.

[5] W. Yang, and Q. Li, "The expanded Morison equation considering inner and outer water hydrodynamic pressure of hollow piers", Ocean Engineering, vol. 69, pp. 79-87, 2013.

[6] H. Liu, B. Wang, and L. Xue, "Recent progress in wave-current loads on foundation structure with piles and cap", Applied Mathematics and Mechanics, vol. 34, no.10, pp. 1098-1109, 2013.

[7] O.M. Faltinsen, J.N. Newman, and T. Vinje, "Nonlinear-wave loads on a slender vertical cylinder", Journal of Fluid Mechanics, vol. 289, pp. 179-98, 1995.

[8] Y. Li, and F. Wang, "Wave-current forces on two piles", Journal of Hydrodynamics, vol. 7, no. 1, pp. 141-149, 1992.

[9] A. Zakeri, and B. Hawlader, "Drag forces caused by submarine glide block or out-runner block impact on suspended (free-span) pipelines-Numerical analysis", Ocean Engineering, vol. 67, pp. 8999, 2013.

[10] M. Zeinoddini, H. Arabzadeh, M. Ezzati, and G.A.R. Parke, "Response of submarine pipelines to impacts from dropped objects: Bed flexibility effects", International Journal of Impact Engineering, vol. 62, pp. 129-41, 2013.

[11] X.L. Zhou, J.H. Wang, J. Zhang, and D.S. Jeng, "Wave and current induced seabed response around a submarine pipeline in an anisotropic seabed", Ocean Engineering, vol. 75, pp. 112-27, 2014.

[12] P.H. Taylor, H. Santo, and Y.S. Choo, "Current blockage: Reduced Morison forces on space frame structures with high hydrodynamic area, and in regular waves and current", Ocean Engineering, vol. 57, pp. 11-24, 2013.

[13] W. Yang, and Q. Li, "The expanded Morison equation considering inner and outer water hydrodynamic pressure of hollow piers", Ocean Engineering, vol. 69, no. 69, pp. 79-87, 2013.

[14] J. Wolfram, and M. Naghipour, "On the estimation of Morison force coefficients and their predictive accuracy for very rough circular cylinders", Applied Ocean Research, vol. 21, no. 6, pp. 311328, 1999.

[15] Y. Zhu, Wave Mechanics for Ocean Engineering. Tianjin University Press: Tianjin 1991.

[16] A. Techet, Design Principles for Ocean Vehiclcs. Massachusetts Institute of Technology (MIT): USA, 2005.

[17] CCCC First Harbor Consultants Co, Code of Hydrology for Sea Harbour. China Communications Press, 1998. (in Chinese)

\author{
Received: December 15, 2014 \\ Revised: January 04, 2015 \\ Accepted: February 25, 2015 \\ (C) Zhang et al.; Licensee Bentham Open.
}

This is an open access article licensed under the terms of the Creative Commons Attribution Non-Commercial License (http://creativecommons.org/licenses/by-nc/3.0/) which permits unrestricted, non-commercial use, distribution and reproduction in any medium, provided the work is properly cited. 